\title{
Two-stage arthrodesis of the ankle joint in the treatment of periprosthetic infection
}

\author{
N.M. Kliushin, A.M. Ermakov
}

National Ilizarov Medical Research Centre for Orthopaedics and Traumatology, Kurgan, Russian Federation

\begin{abstract}
Introduction The main reasons for arthroplasty of the ankle joint are osteoarthritis in the terminal stage (posttraumatic or idiopathic), purulent arthritis and oncology. Publications devoted to the problems of infectious complications after arthroplasty of the ankle are not numerous. The rate of periprosthetic ankle infection varies from $2.4 \%$ to $4.7 \%$ of cases; and the predisposing factors include diabetes mellitus, previous history of operations on the joint and the duration of the arthroplasty procedure. The restorative strategy for periprosthetic infection involves diagnostic measures (hematological, radiological, microbiological, radiologic, cytological) and surgical treatment. The variants of surgical treatment of periprosthetic infection of the ankle joint are revision arthroplasty (single- or two-staged), arthrodesis (using external fixation devices and intramedullary nail) and amputation. Moreover, along with surgical intervention, a long-term course of etiotropic therapy (antibacterial and/or antifungal) is mandatory. Methods The result of treatment of a patient with periprosthetic ankle infection using a two-stage arthrodesis procedure was analyzed. Results The medical measures arrested the purulent inflammatory process and enabled the weight-bearing function of the limb. Discussion Two-stage arthrodesis of the ankle may be one of the options for treating periprosthetic infection aimed at maintaining the support function of the limb and its length without the use of additional orthopedic procedures, such as osteotomy for lengthening to cover the post-resection bone defect, thereby reducing the risk of possible complications (damage to the main vessels and nerves in the area of the osteotomy) and the period of surgical rehabilitation of the patient.
\end{abstract}

Keywords: arthroplasty, ankle joint, periprosthetic infection, spacer, two-stage arthrodesis

The main reasons for ankle joint arthroplasty are osteoarthritis in the terminal stage (posttraumatic or idiopathic), purulent arthritis and oncology. Publications devoted to the problem of infectious complications after arthroplasty of the ankle are not numerous. The rate of periprosthetic ankle infection varies from $2.4 \%$ to $4.7 \%$ of cases; and the predisposing factors include diabetes mellitus, previous history of operations on the joint and duration of the arthroplasty procedure [3-6]. The treatment strategy for periprosthetic infection involves diagnostic measures (hematological, radiological, microbiological, radiological, cytological) and surgical treatment $[7,8,9]$. The variants of surgical treatment of periprosthetic infection of the ankle joint are revision arthroplasty (single- or two-stage), arthrodesis (using external fixation devices or intramedullary nail) and amputation [10, 11]. Moreover, along with surgical intervention, a long-term course of etiotropic therapy (antibacterial and/or antifungal) is mandatory $[12,13]$.

We present a case of successful treatment of periprosthetic infection of the ankle joint with a technique of two-stage arthrodesis.

Patient Z., 32 years old, was admitted to our clinic in October 2016 with a diagnosis of late chronic periprosthetic infection of the left ankle joint (according to Tsukayama) [14], chronic post-traumatic osteomyelitis of the left tibia and talus, fistulous type, flexion-extension contracture of the left ankle joint (Fig. 1). Concomitant diseases were chronic viral hepatitis " $\mathrm{C}$ " of a minimum activity, chronic bronchitis in remission.

At admission, the patient complained of the sinus with discharge in the area of the ankle joint and restricted range of joint motion.

Disease history The patient sustained a closed fracture of the lateral malleolus falling from 1.5 height in 2013. A plaster cast was applied for three months at the hospital of his residence. In 2014, he started to experience severe pain and limited function in the left ankle joint. In September 2015, total joint replacement was performed for left-side arthritis in the terminal stage. In December 2015, pain in the left ankle and increased body temperature appeared. At his residence hospital, exposure and drainage of purulent arthritis was performed twice. Then, a sinus formed in the area of the involved joint.

When examined, the patient moved with crutches, had severe pain in the left ankle joint. There was no difference in limb length. At admission, the functioning of the left ankle joint was rated with 29 points (AOFAS). 

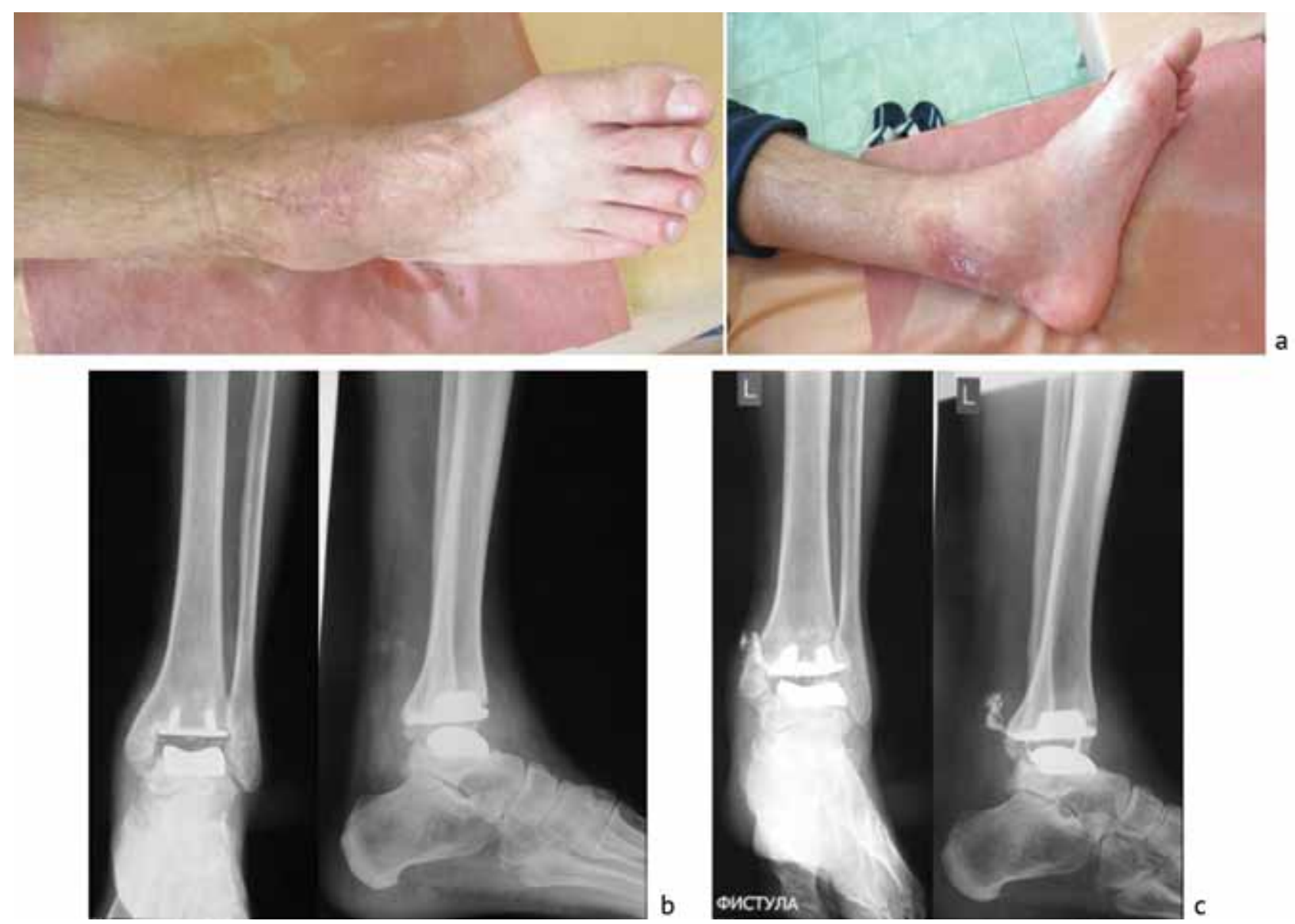

Fig. 1 Local status before treatment $\boldsymbol{a}$; radiographs of the left ankle joint $\boldsymbol{b}$; $\boldsymbol{c}$ fistulograms of the left ankle joint

Radiographs showed that the implant components were stable.

Blood tests confirmed the infectious process, increased ESR $(47 \mathrm{~mm} / \mathrm{h})$, other blood counts were within the normal range.

The first stage of arthrodesis of the left ankle joint was performed in October 2016 which included surgical approach to the joint with excision of the sinus and the old postoperative scar, removal of infected components of the implant using a revision tool kit and radical surgical debridement of the infection site. Tissues were abundantly treated with antiseptic solutions (lavacept and betadine) using ultrasound cavitation. Next, a block-shaped spacer was implanted that was produced from a pack of bone cement (40 grams) impregnated with antibacterial drugs (5 grams of vancomycin and $640 \mathrm{mg}$ of gentamicin) (Fig. 2). The wound was sutured in layers without drainage. Four days after the operation, the results of an intraoperative microbiological study were obtained harvested from the tissues of the left ankle joint and from the surface of the removed components of the implant and revealed Staphylococcus aureus $10 \times 4$. The course of etiotropic therapy was administered for six weeks (rifampicin and augmentin). The limb was immobilized with a plaster cast for a period of one month.

The patient was mobilized on the second postoperative day assisted by an exercise therapy instructor. Inpatient stay was 21 days.

The second stage of arthrodesis was performed in April 2017 that included arthrotomy, removal of the spacer, collection of tissues and spacer elements for microbiological study. Joint tissues were abundantly treated with antiseptic solutions (lavacept and betadine) using ultrasound cavitation. Following this, the articular cavity was tightly impacted by the graft chips mixed with one gram of vancomycin. The wound was sutured in layers without drainage. The left lower leg and foot were stabilized with the Ilizarov apparatus in order to produce compression at the level of the joint (Fig. 3). The results of intraoperative microbiological studies did not reveal any pathogenic growth. Taking into account the microbiological tests after the first operation, a course of etiotropic therapy was prescribed for six weeks (rifampicin and augmentin). 

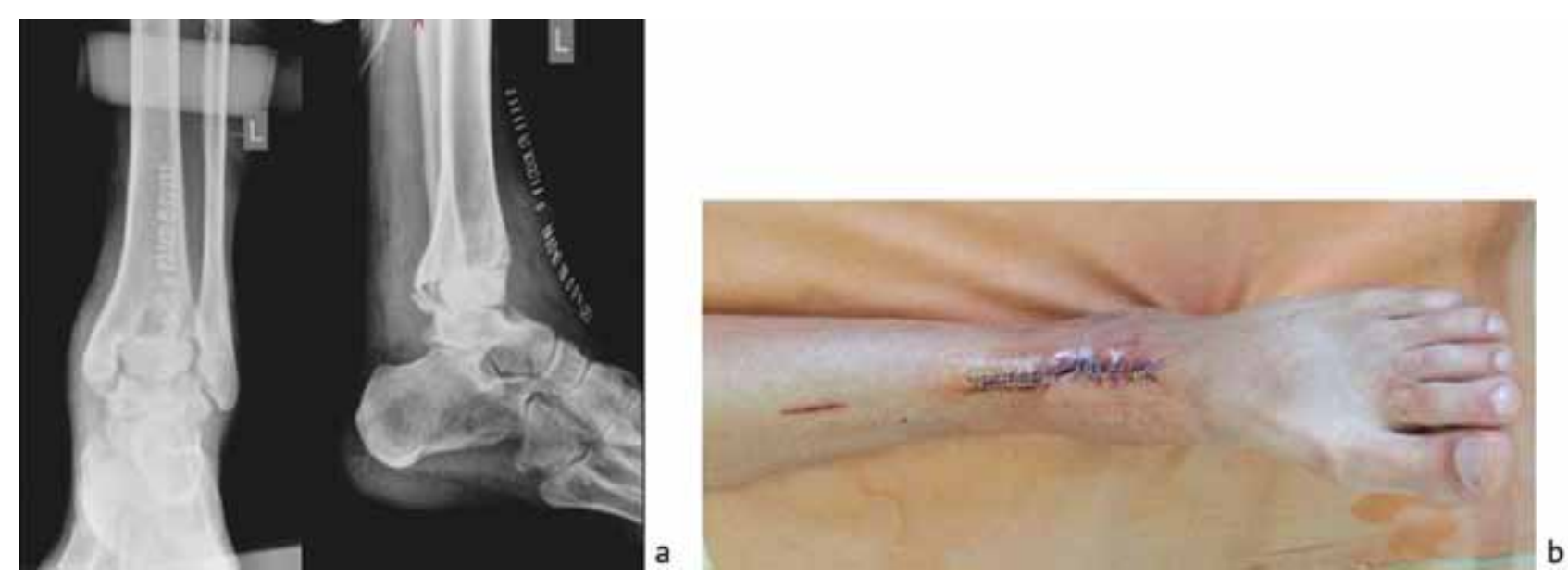

Fig. 2 After the first stage of treatment: $\boldsymbol{a}$ radiographs of the left ankle joint; $\boldsymbol{b}$ local status
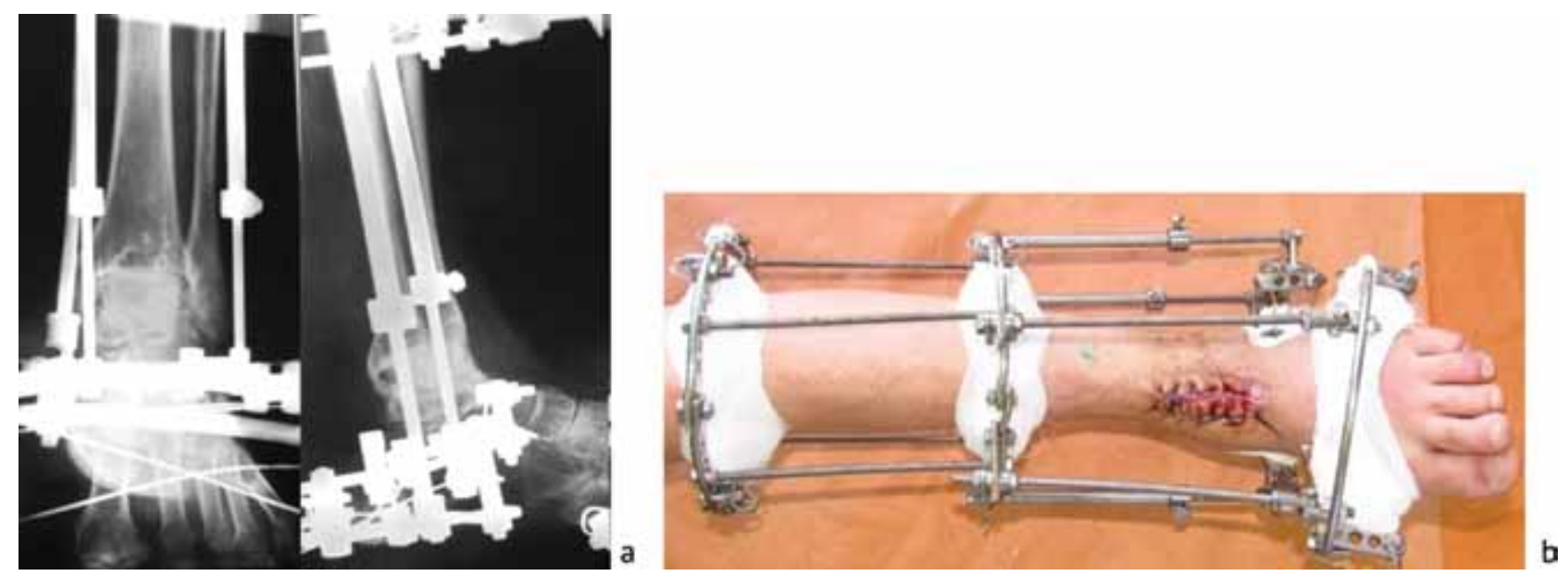

Fig. 3 After the second stage of treatment: $\boldsymbol{a}$ radiographs of the left ankle joint; $\boldsymbol{b}$ local status

The patient was active on the second day after surgery under supervision of an exercise therapy instructor. The wound healed by primary intention. The sutures were removed on days 17 to 19 after surgery at his residence clinic. The duration of inpatient treatment was 18 days. The dismantling of the Ilizarov apparatus was performed five months after the operation.
At one-year follow-up, exacerbation of the purulent inflammatory process was not revealed. Clinical and radiological signs of consolidation were between the allograft and the bone tissue, no destructive changes were observed; hematological markers of inflammation were within normal limits (leukocytes - $5.5 \times 10^{9} / \mathrm{L}$; ESR $10 \mathrm{~mm} /$ hour; CRP - $3.9 \mathrm{mg} / \mathrm{l})$. The functional condition of the left ankle joint was 69 AOFAS points (Fig. 4).
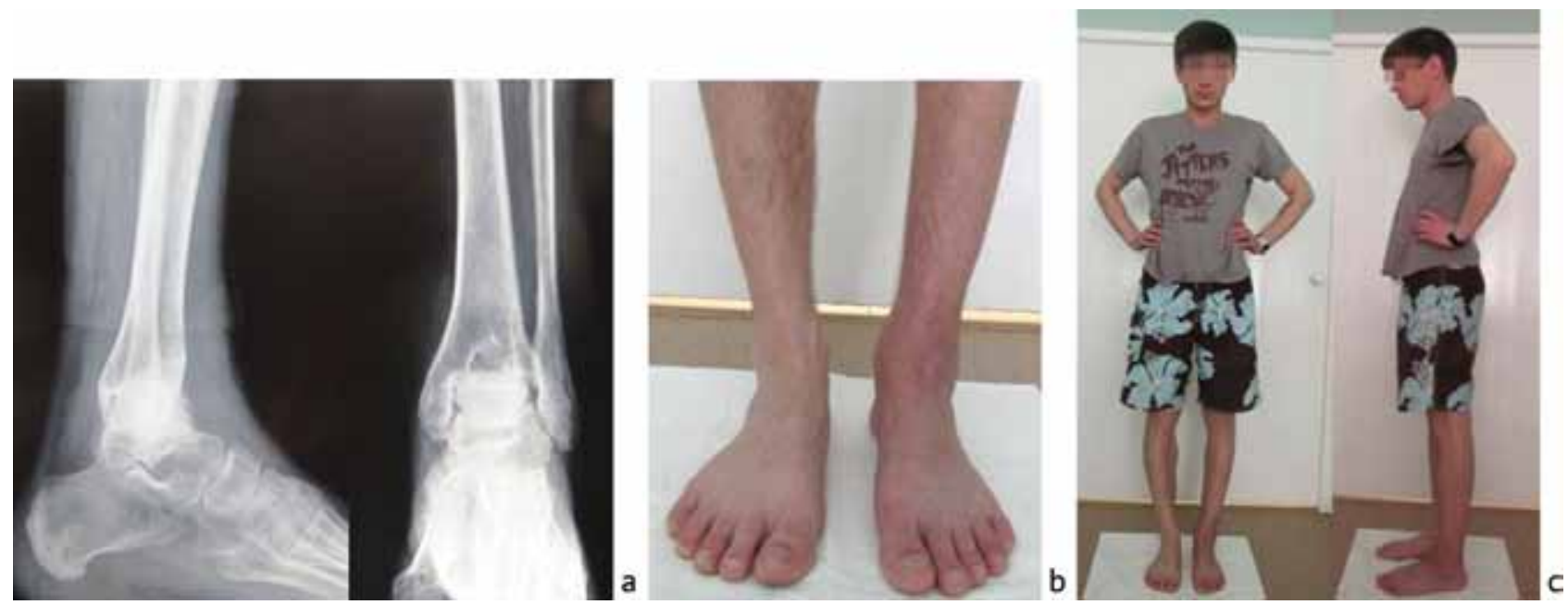

Fig. 4 A year after treatment: $\boldsymbol{a}$ radiographs of the left ankle joint; $\boldsymbol{b}$ local status; $\boldsymbol{c}$ result of the treatment 
The patients was satisfied with the outcome. He does not use crutches and bears full weight.

Two-stage arthrodesis of the ankle joint is one of the options for treatment of periprosthetic infection which preserves the function and length of the limb without additional orthopedic interventions, such as lengthening osteotomies for a post-resection bone defect as well as reduces the risk of possible complications (trauma to the main vessels and nerves in the osteotomy zone) and saves the time of surgical rehabilitation.

\section{REFERENCES}

1. Alrashidi Y., Galhoum A.E., Wiewiorski M., Herrera-Pérez M., Hsu R.Y., Barg A., Valderrabano V. How to diagnose and treat infection in total ankle arthroplasty. Foot Ankle Clin., 2017, vol. 22, no. 2, pp. 405-423. DOI: 10.1016/j.fcl.2017.01.009.

2. Frank R.M., Cross M.B., Della Valle C.J. Periprosthetic joint infection: modern aspects of prevention, diagnosis, and treatment. J. Knee Surg., 2015, vol. 28, no. 2, pp. 105-112. DOI: 10.1055/s-0034-1396015.

3. Gougoulias N., Khanna A., Maffulli N. How successful are current ankle replacements?: a systematic review of the literature. Clin. Orthop. Relat. Res., 2010, vol. 468, no. 1, pp. 199-208. DOI: 10.1007/s11999-009-0987-3.

4. Holzmann T., Schneider-Brachert W. Microbiological diagnosis of periprosthetic joint infections. Orthopade, 2015, vol. 44, no. 5, pp. 344-348. DOI: 10.1007/s00132-015-3087-y.

5. Ilchmann T., Zimmerli W., Ochsner P.E., Kessler B., Zwicky L., Graber P., Clauss M. One-stage revision of infected hip arthroplasty: outcome of 39 consecutive hips. Int. Orthop., 2016, vol. 40, no. 5, pp. 913-918. DOI: 10.1007/s00264-015-2833-4.

6. Jakobs O., Schoof B., Klatte T.O., Schmidl S., Fensky F., Guenther D., Frommelt L., Gehrke T., Gebauer M. Fungal periprosthetic joint infection in total knee arthroplasty: a systematic review. Orthop. Rev. (Pavia), 2015, vol. 7, no 1, pp. 5623. DOI: 10.4081/ or.2015.5623.

7. Kessler B., Sendi P., Graber P., Knupp M., Zwicky L., Hintermann B., Zimmerli W. Risk factors for periprosthetic ankle joint infection: a case-control study. J. Bone Joint Surg. Am., 2012, vol. 94, no. 20, pp. 1871-1876. DOI: 10.2106/JBJS.K.00593.

8. Lampert C. Ankle joint prosthesis for bone defects. Orthopade, 2011, vol. 40, no. 11, pp. 978-83. DOI: 10.1007/s00132-011-1826-2.

9. Mazur J.M., Schwartz E., Simon S.R. Ankle arthrodesis. Long-term follow-up with gait analysis. J. Bone Joint Surg. Am., 1979, vol. 61, no. 7, pp. 964-975.

10.Mazzucchelli L., Rosso F., Marmotti A., Bonasia D.E., Bruzzone M., Rossi R. The use of spacers (static and mobile) in infection knee arthroplasty. Curr. Rev. Musculoskelet. Med., 2015, vol. 8, no. 4, pp. 373-382. DOI: 10.1007/s12178-015-9293-8.

11.McCoy T.H., Goldman V., Fragomen A.T., Rozbruch S.R. Circular external fixator-assisted ankle arthrodesis following failed total ankle arthroplasty. Foot Ankle Int., 2012, vol. 33, no. 11, pp. 947-955. DOI:10.3113/FAI.2012.0947.

12.Myerson M.S., Shariff R., Zonno A.J. The management of infection following total ankle replacement: demographics and treatment. Foot Ankle Int., 2014, vol. 35, no. 9, pp. 855-62. DOI: 10.1177/1071100714543643.

13.Patton D., Kiewiet N., Brage M. Infected total ankle arthroplasty: risk factors and treatment options. Foot Ankle Int., 2015, vol. 36, no. 6, pp. 626-634. DOI: 10.1177/1071100714568869.

14.Tsukayama D.T., Estrada R., Gustilo R.B. Infection after total hip arthroplasty. A study of the treatment of one hundred and six infections. J. Bone Joint Surg. Am., 1996, vol. 78, no. 4, pp. 512-523. DOI: 10.2106/00004623-199604000-00005.

Received: 21.06.2019

\section{Information about the authors:}

1. Nikolai M. Kliushin, M.D., Ph.D., National Ilizarov Medical Research Centre for Orthopaedics and Traumatology, Kurgan, Russian Federation, Email: klyushin_nikolay@mail.ru

2. Artem M. Ermakov, M.D., Ph.D., National Ilizarov Medical Research Centre for Orthopaedics and Traumatology, Kurgan, Russian Federation, Email: ema_cab@mail.ru 